\title{
Performance effect of applying paraffin wax on solar photovoltaic backplate
}

\author{
E. Roslan, A. Razak \\ Department of Mechanical, College of Engineering, Universiti Tenaga Nasional, Malaysia
}

\begin{tabular}{l} 
Article Info \\
\hline Article history: \\
Received Sep 1, 2018 \\
Revised Nov 25, 2018 \\
Accepted Dec 13, 2018 \\
\hline
\end{tabular}

Keywords:

Panel efficiency

Phase change material

Solar photovoltaic

\begin{abstract}
The efficiency of solar photovoltaic (PV) panels is affected by its operating temperature. Having high irradiance produces high electrical output but also heats up the panel and reducing the panels efficiency. This study investigates the effect of cooling solar PV panels using $750 \mathrm{~g}$ of paraffin wax as phase change material (PCM) applied to the back plate of a solar PV panel. The experiment is done at Kajang, Selangor, Malaysia. The result is reduction of up to $9.5^{\circ} \mathrm{C}$, increase of up to $0.947 \mathrm{~W}$ or $11.82 \%$ of electrical power output when compared to the panel without any PCM applied. The panel cooled with PCM also produced $4.69 \%$ more energy.
\end{abstract}

Copyright @ 2019 Institute of Advanced Engineering and Science. All rights reserved.

\section{Corresponding Author:}

Mohd Eqwan bin Mohd Roslan,

Department of Mechanical, College of Engineering,

Universiti Tenaga Nasional,

Jalan IKRAM-UNITEN, 43000 Kajang, Selangor, Malaysia.

Email: eqwan@uniten.edu.my

\section{INTRODUCTION}

Located on the equator, Malaysia is blessed with the abundance of solar irradiance making it suitable for solar photovoltaic (PV) installation. This has been well exploited with Malaysia giving focus on installing solar PV systems throughout the country. Up until 2018, solar PV consists of $381.47 \mathrm{MW}$ of installed capacity or $66.42 \%$ of the total Renewable Energy technologies installed under the Feed-in-tariff scheme [1]. Malaysia has also awarded 1.228GW of Large Scale Solar projects and is expected to be fully operational by 2020 [2]. However, having the abundance of sunlight not only bring usable energy but also heat that will affect the performance of solar panels. An average decrease of $0.25-0.3 \%$ solar PV panel efficiency is estimated for every Celsius increase of solar PV panel temperature, depending on the material used [3]. This results not only in losses of electrical output but also a waste of space due to less output obtained per square meter of PV installed. The effect of increasing temperature on solar PV performance can be seen in Figure 1 [4].

Various methods have been tested in the attempt to cool down panel temperature and increase the electrical outputs. A recent comprehensive review was done by Siecker et. al. on solar PV cooling technologies including floating, water spraying, heat sink, forced air and water circulation, phase-changematerials (PCM), immersion, coating and thermoelectric cooling [5]. The techniques can be generalized into two, active and passive methods. Active methods require external energy to operate such as using electricity for pumps and passive methods not requiring any external energy to operate. One of the passive methods is using PCM to absorb the heat from solar panels. Hasan et. al. has evaluated the use of PCM as a means of thermal regulation to enhance the performance of building-integrated solar PV and has summarized the advantages including high heat transfer rate and heat absorption, passive heat exchange with no noise and no 
maintenance cost [6]. However, he also noted the disadvantages of using PCM including toxicity, fire safety issue, corrosiveness and disposal [6].

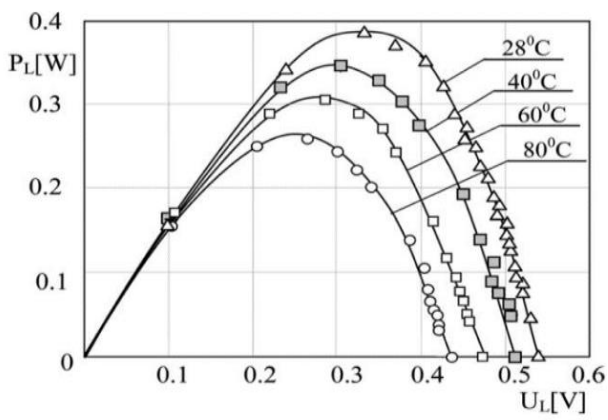

Figure 1. Effect of temperature on power output of solar PV

This study investigates the effect of using paraffin wax as PCM on the performance of solar PV performance. The advantage and disadvantage of using paraffin wax are in Table 1[7].

Table 1. Advantages and Disadvantages of PCM [7]

\begin{tabular}{cc}
\hline Advantage & Disadvantages \\
\hline Reliable & Low thermal conductivity \\
Predictable & No compatibility with plastic containers \\
Moderately flammable & \\
Non-corrosive & \\
Chemically inert & \\
Stable below 500 0C & \\
\hline
\end{tabular}

\section{RESEARCH METHOD}

The site selected was at TNB Research Sdn. Bhd., located in Kajang, Malaysia, on an open space without any shade to avoid any loss of sunlight. The location is selected due to the location of the measurement equipment being borrowed for this study.

The PCM used for this is paraffin wax, which has a melting point of $30^{\circ} \mathrm{C}$. The melting point is higher than the Standard Testing Condition for solar panels but also lower than the environmental temperature at the location during noon. The price is also within the budget, costing RM60 for a $\mathrm{kg}$ of the material. The material is expected to lower the temperature of the panel by absorbing the heat from the panel and changing its state to liquid when the temperature increases above its melting point. $750 \mathrm{~g}$ of the materials were used by filling an aluminium container and attaching it to the back of the solar PV panel. The physical properties of the PCM used in this study is as in Table 2.

Table 2. Physical Properties of PCM Used in this Study

\begin{tabular}{cc}
\hline Property & Value \\
\hline Melting Point $\left({ }^{\circ} \mathrm{C}\right)$ & 30 \\
Latent Heat $(\mathrm{kj} / \mathrm{kg})$ & 226 \\
Density $\left(10^{3} \mathrm{~kg} / \mathrm{m}^{3}\right)$ & 1.40 \\
Thermal Conductivity $(\mathrm{W} / \mathrm{m} . \mathrm{K})$ & 0.55 \\
\hline
\end{tabular}

Two panels are used, one with PCM attached to the back and one without PCM attached as the control setup. The panels are placed on a stand to avoid heat trapping beneath the panels. The measurement devices are connected to the MC4 wires of the panels and together with the multimeter to measure the current and voltage output of the panels. All the measurement devices are connected to a computer for data reading. Overall experimental setup consists solar power meter for solar irradiation detection, two set of solar PV which one of it being attached with PCM and another one is without PCM, two multi-meters for I-V 
measurements, wind speed meter for wind velocity measurements together with humidity and the surface temperature, and last but not least, personal computer for data storage. The schematic diagram for overall setup is shown in Figure 2 below.

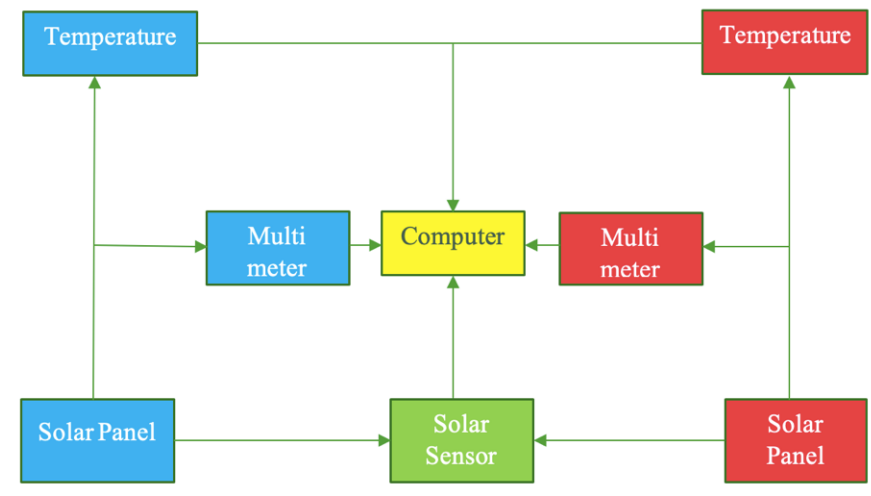

Figure 2. Schematic for experiment setup

During the experiment, the temperatures of each panel and the surrounding air temperature are measured. Also, another important parameter of raw data is collected within 15 minutes in 4- hours' period of experiment during the peak hours of optimum radiation of sunlight starting at $11.00 \mathrm{pm}$ until $3.00 \mathrm{pm}$ o'clock for three days. These parameters are recorded in the table and are calculated by using a Microsoft Excel.

Then, the data for solar irradiance, current, voltage, power input, power output, solar PV efficiency as well as the data of the wind speed or velocity to observe any irregular effect for both solar panels are recorded. formula:

Using the data obtained from the meters, the electrical power output is calculated using the power

$$
P=I \times V
$$

using:

The panel efficiency, defined as the electrical output over the irradiance from the sun, is calculated

$\eta=\frac{P_{\text {electrical }}}{P_{\text {irradiance }}}=\frac{I \times V}{E \times A} \times 100 \%$

where:

$I=$ current $;=$ voltage $; E=$ solar $\frac{\text { irradiance }}{m^{2}} ; A=$ panel area

Graphs of panel temperature vs. environment temperature and power output vs. time for panels with and without PCM. The energy output for both panels are calculated using :

$E=\sum_{t=0}^{n} P \times t$

Where:

$t=$ time $; n=$ final interval $;=$ electrical power output;

\section{RESULTS AND ANALYSIS}

Figure 3 shows the irradiance recorded for Day 1 until Day 3. The irradiance was recorded starting 11.00 a.m. until 3.00 p.m. on each day. It can be seen that for the period, the irradiance kept increasing with drops intermittently before decreasing at the end. For Day 2, the irradiance is much more erratic. The sudden drops can be attributed to passing clouds, which significantly affects the amount of irradiance reaching the surface. The highest irradiance recorded was on Day 2 at 1 p.m. in the afternoon, reaching a peak of 
$1181 \mathrm{~W} / \mathrm{m}^{2}$. The irradiance on Day 1 of the experiment was relatively low due to the cloudy weather. The amount of solar irradiance on the solar panel or power input is dependent on the size of the solar panel. The results for Day 3 will be discussed in detailed in the following section due to having the best weather of the three days.

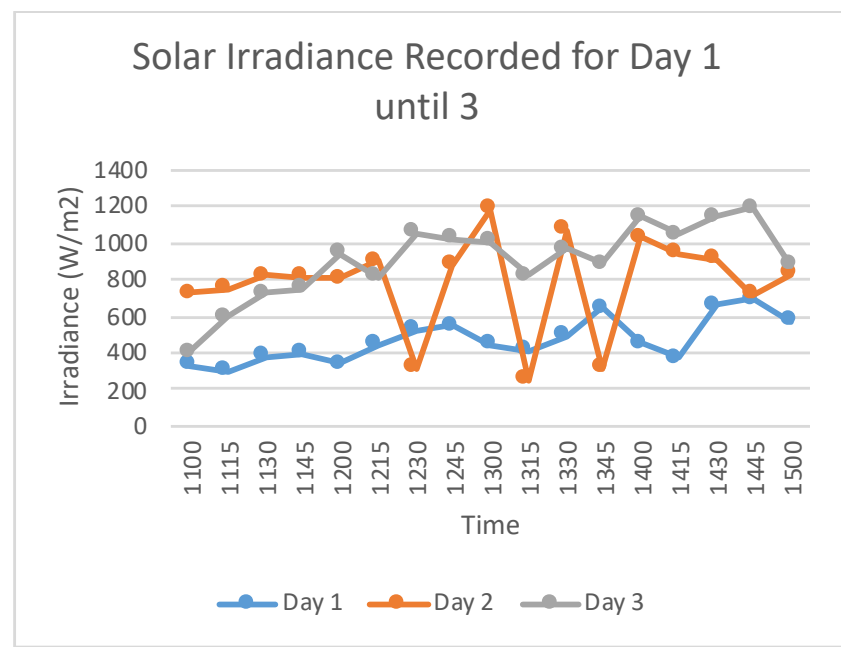

Figure 3. Irradiance recorded for three days

Figure 4 Shows the panel temperature against the environment temperature. The highest panel temperature recorded was on the panel without PCM at $63.2^{\circ} \mathrm{C}$. The lowest is $42.3^{\circ} \mathrm{C}$ on the panel with $\mathrm{PCM}$. It can be seen that at the same ambient temperature, the panel with PCM consistently has lower temperature compared to the panel without PCM. The panel with PCM achieved up to $9.5^{\circ} \mathrm{C}$ lower temperature compared to the panel without PCM. These show that the PCM served its objective of lowering the panel temperature. However, it should be noted that the PCM has its thermal capacity, at which after absorbing enough heat and changing phase completely, will increase in temperature. In this study, it is not determined whether all the PCM has absorbed enough heat to completely change phase to liquid.

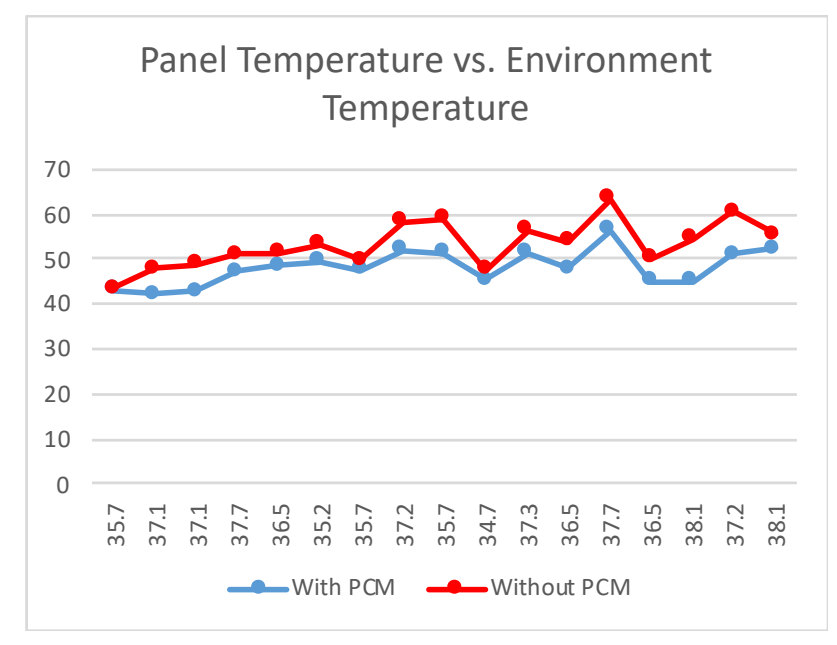

Figure 4. Panel temperatures vs. environment temperatures

Figure 5 shows the power outputs for both panels throughout the data collection time. Except for the first point of time, panel with PCM consistently produce higher power output compared to the panel without 
PCM. The highest power output difference is at $0.947 \mathrm{~W}$ or $11.82 \%$ more power output for the panel with PCM compared to without PCM, occurring at 1430.

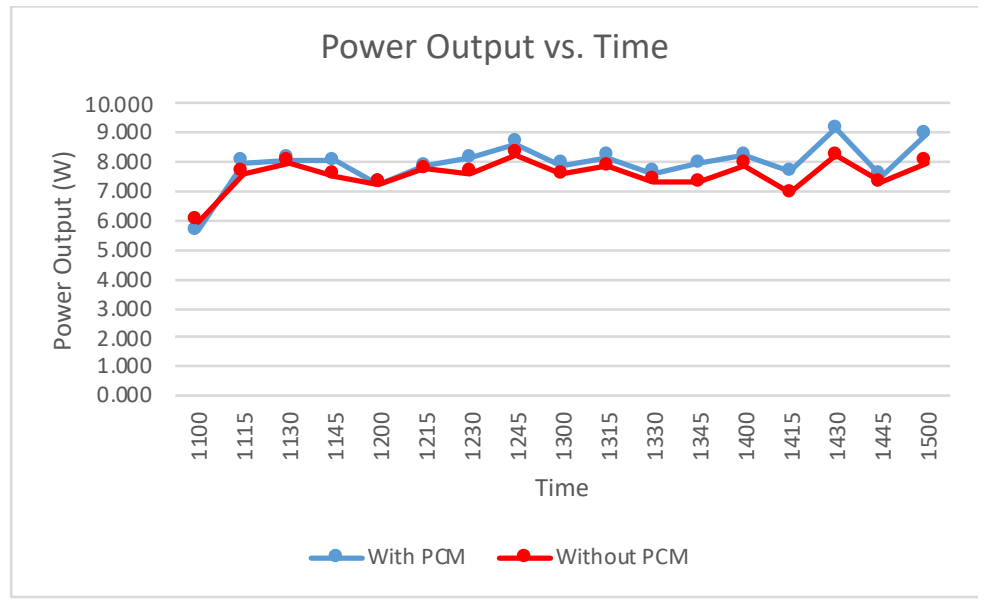

Figure 5. Power output of panels vs. time of day

Table 3 shows the comparison of energy production between the solar panel with paraffin wax as PCM applied at the backplate of solar PV panel for cooling and without PCM. For four hours each day for three days, the energy production for panel with PCM is $90.403 \mathrm{Wh}$ compared to $86.353 \mathrm{Wh}$ for the panel without PCM. The panel with PCM cooling its backplate produced $4.051 \mathrm{Wh}$ or $4.69 \%$ more energy compared to the one without PCM. This means that for the same amount of area of solar PV installed, a higher concentration of energy can be produced. This will save land or surface area, or more can be produced in the same amount of are when PCM is applied for backplate cooling. Depending on the cost of installation of backplate cooling, it has potential to give additional return for the energy sold to the grid either through feed-in-tariff or net-energy-metering, hence lowering its payback period or increasing its ROI. For commercial or residential application, a better design process of applying the backplate cooling method is needed, which is not covered in this research. In the case of this project, the cost of applying the PCM is $37.5 \%$ of the panel alone, without inverters and wiring cost typical with residential and commercial installation. If included, the percentage cost of PCM application will be lower. The optimal amount of PCM is also not evaluated in this experiment.

Table 3. Total Energy Produced

\begin{tabular}{ccc}
\hline \multirow{2}{*}{ Day } & \multicolumn{2}{c}{ Energy Produced (Wh) } \\
\cline { 2 - 3 } & With PCM & Without PCM \\
\hline 1 & 24.239 & 23.5623 \\
2 & 32.4965 & 30.7097 \\
3 & 33.6675 & 32.0806 \\
Total & 90.403 & 86.353 \\
\hline
\end{tabular}

\section{CONCLUSION}

Using PCM to absorb heat from the solar panel backplate affects the temperature of the panel by cooling it down, hence decreasing the temperature and producing higher electrical output, up to $11.82 \%$ higher power output. Throughout the four hours for three days, the panel with PCM produces $4.051 \mathrm{Wh}$ more energy compared to the panel without PCM. This translates into $4.69 \%$ more energy. Future study could include the heat transfer study the determine the optimal quantity of PCM to be used and cost benefit analysis to determine whether the cost of installing PCM is justified by the additional energy produced.

\section{ACKNOWLEDGEMENTS}

We would like to acknowledge TNB Research Sdn. Bhd. for providing the equipment and space for the experiment. 


\section{REFERENCES}

[1] SEDA Malaysia, "Installed Capacity (MW) of Commissioned RE Installations." [Online]. Available: http://seda.gov.my/?omaneg=00010100000001010101000100001000000000000000000000\&s=539. [Accessed: 04Nov-2018].

[2] J. Wong, "Malaysia awards 1,228MW projects," The Star Online.

[3] F. Grubisic-Cabo, S. Nizetic, and T. G. Marco, "Photovoltaic Panels : a Review of the Cooling," Trans. Famena XL, vol. 1, no. 1, pp. 63-74, 2016.

[4] E. Radziemska, "The effect of temperature on the power drop in crystalline silicon solar cells," Renew. Energy, vol. 28, pp. 1-12, 2003.

[5] J. Siecker, K. Kusakana, and B. P. Numbi, "A review of solar photovoltaic systems cooling technologies," Renew. Sustain. Energy Rev., vol. 79, no. July 2016, pp. 192-203, 2017.

[6] A. Hasan, S. J. McCormack, M. J. Huang, and B. Norton, "Evaluation of phase change materials for thermal regulation enhancement of building integrated photovoltaics," Sol. Energy, vol. 84, no. 9, pp. 1601-1612, 2010.

[7] A. Sharma, V. V. Tyagi, C. R. Chen, and D. Buddhi, "Review on thermal energy storage with phase change materials and applications," Renew. Sustain. Energy Rev., vol. 13, no. 2, pp. 318-345, 2009. 